\title{
Value transfer in simultaneous object discriminations by rats
}

\author{
JEROME S. COHEN, CHRISTINE DRUMMOND, and NICOLE TERRELONGE \\ University of Windsor, Windsor, Ontario, Canada
}

\begin{abstract}
Increasing the amount of sunflower seeds under a baited object when it occurs either within or external to a simultaneous object discrimination increases the value transferred to the nonbaited object. Rats were trained with two object discriminations, $\mathrm{A}^{1} \mathrm{~B}^{0}$ and $\mathrm{C}^{1} \mathrm{D}^{0}$, where the superscript refers to the number of sunflower seeds obtained for pushing aside the object. The amount under A was increased to six on other trials in which the $\mathrm{A}^{6}$ or $\mathrm{C}^{1}$ object alternated with regular $\mathrm{A}^{1} \mathrm{~B}^{0}$ or $\mathrm{C}^{1} \mathrm{D}^{0}$ discrimination trials. The $\mathrm{A}$ and $\mathrm{C}$ objects on the alternating trials were presented alone (Experiment 1), with a common nonbaited object $\left(\mathrm{A}^{6} \mathrm{X}^{0}\right.$ and $\mathrm{C}^{1} \mathrm{X}^{0}$; Experiments 2 and 3$)$, or with two different nonbaited objects $\left(\mathrm{A}^{6} \mathrm{X}^{0}\right.$ and $\mathrm{C}^{1} \mathrm{Y}^{0}$; Experiment 4). Subsequent probe tests with pairs of usually nonbaited objects (e.g., $\left.\mathrm{B}^{1} \mathrm{D}^{1}, \mathrm{X}^{1} \mathrm{Y}^{1}\right)$ showed that the rats preferredB to D in Experiments 1-3, but not in Experiment 4, where they preferred X to Y. These preferences cannot be accounted for solely by differential inhibition, because initial training with only $\mathrm{A}^{1} \mathrm{~B}^{0}$ and $\mathrm{C}^{1} \mathrm{D}^{0}$ discriminations in three of the four experiments prevented the rats from making or greatly reduced their making more nonreinforced responses within the $\mathrm{C}^{1} \mathrm{D}^{0}$ than within the $\mathrm{A}^{1} \mathrm{~B}^{0}$ discrimination. Therefore, these preferences must be considered to reflect a value transfer effect. Other preference probe tests between X or Y and B or D in Experiments 2-4 revealed a possible differential inhibition effect, however, since the rats preferred a more recently introduced nonbaited object to an originally presented nonbaited object regardless of which baited object had accompanied it.
\end{abstract}

The value transfer (VT) hypothesis (Fersen, Wynne, Delius, \& Staddon, 1991) maintains that some portion of the reinforcing value of $S+$ transfers to $S-$ in a simultaneous discrimination. Accordingly, the amount of the positive value transferred to $S-$ should be directly related to the amount of reinforcement to $\mathrm{S}+$. This prediction is borne out in some recent studies (Dorrance, Kaiser, \& Zentall, 1998; Zentall \& Sherburne, 1994; Zentall, Sherburne, Roper, \& Kraemer, 1996) with pigeons trained on two concurrent simultaneous color discriminations $(\mathrm{A}+\mathrm{B}-$, $\mathrm{C}+\mathrm{D}-$ ) in which the probability of reinforcement for responding to A was greater than that for responding to $\mathrm{C}$. When the birds were tested for their B versus D preferences, they consistently chose $\mathrm{B}$, the stimulus paired with the more positive $\mathrm{A}$, over $\mathrm{D}$, the stimulus paired with the less positive $C$. This effect was observed whether $A$ was made more positive within the $\mathrm{A}+\mathrm{B}-$ and $\mathrm{C}+\mathrm{D}-$ discrimination context (Zentall \& Sherburne, 1994; Zentall

Findings from Experiment 1 of this study were originally reported at the International Conference on Comparative Cognition, Melbourne Beach, Florida (March, 2000). The present research was supported by an operating grant to J.S.C. and an undergraduate research assistantship grant to C.D. from the Natural Sciences and Engineering Research Council of Canada. Additional funds were provided by the Ontario Work Study Program and the Summer Careers Opportunity Program of Human Resources and Development Canada. We gratefully acknowledge the assistance of Michelle Pepin, who helped in carrying out the first experiment. Correspondence concerning this article should be addressed to J. S. Cohen, Department of Psychology, University of Windsor, Windsor, ON, N9V 2M6 Canada (e-mail: a77@uwindsor.ca). et al., 1996, Experiments 1 and 2) or on off-baseline trials (Dorrance et al., 1998; Zentall et al., 1996, Experiment 3). Dorrance et al. noted that this effect is contrary to the occasion-setting hypothesis, which predicts that birds should avoid B (and thus choose D) because the former had come to signal a decrease in reinforcement to its associated A stimulus.

Aitken (1999) reanalyzed Dorrance et al.'s (1998) data to argue that the pigeons' preferences for B over D could have resulted from the development of greater conditioned inhibition to $\mathrm{D}$ than to $\mathrm{B}$ during initial discrimination training. Aitken (1999, see Figure 1, p. 292) found a strong direct relationship $\left(r^{2}=.93\right)$ between $\mathrm{B}$ preference on $\mathrm{BD}$ tests and overall errors to $\mathrm{D}$ during discrimination training. It is noteworthy that Dorrance et al. found that their birds consistently made more errors to $\mathrm{D}$ than to $\mathrm{B}$ during training, except in Experiment 3, where their birds failed to reliably prefer B to D. Although they reported a nonsignificant difference between $\mathrm{B}$ and $\mathrm{D}$ errors in their second experiment, 6 of their 8 pigeons made more $D$ than $B$ errors, 1 showed the same number of errors, and another made more errors to B than to D. Analysis of these data by a Wilcoxon test revealed significantly more $\mathrm{D}$ than $\mathrm{B}$ errors $(T=$ $5.5, p<.05$, one-tailed). Earlier studies from their laboratory (Zentall \& Sherburne, 1994; Zentall et al., 1996, Experiment 1) also reported tendencies, albeit nonsignificant ones, for more D than B errors.

Notwithstanding Zentall, Dorrance, and Clement's (1999) reply to Aitken (1999), we believe that differential experiences with the negative stimuli during training must 
be adequately eliminated to test the VT hypothesis. This may be difficult when the positive value of $\mathrm{S}+$ is determined by its probability of reinforcement, because an animal may simply be more likely to respond to either stimulus in a pair when the $\mathrm{S}+$ is associated with a relatively low probability of reinforcement. Thus, an alternative method for varying the values of the $S+$ stimuli is needed that does not promote differential responding to their respective negative stimuli. One way to do this might be to vary the amount of food as reinforcement for responding to each $\mathrm{S}+$. Moreover, requiring animals to initially acquire each discrimination with equal amounts of food prior to manipulating this factor (cf. Dorrance \& Zentall, 1999 and Zentall et al., 1996, Experiment 3, for similar procedures) might further ensure against systematic differences in responding to each $\mathrm{S}-$.

The major purpose of the present study was to determine whether VT could be obtained in rats trained on concurrent simultaneous object discriminations in which amount (number of sunflower seeds) rather than probability of reinforcement to one of the baited objects was varied. As such, this study was a systematic replication and extension of Dorrance et al. (1998, Experiment 4). It was designed to eliminate differences in nonreinforced responding to each $\mathrm{S}-$ during acquisition of each discrimination. We decided to investigate only value transfer from $S+$ to $S-$, since the question remains as to whether the value of $S-$ can also be transferred to $S+$. In some studies, reducing the negative value of an $S-$ by reinforcing it prior to probe tests does not reliably increase the positive value of its accompanying $\mathrm{S}+(\mathrm{Clem}-$ ent, Weaver, Sherburne, \& Zentall, 1998; Zentall et al., 1996, Experiment 2), whereas in others it does (Dorrance \& Zentall, 1999; Zentall et al., 1996, Experiment 3).

\section{EXPERIMENT 1}

In Dorrance et al. (1998, Experiment 4), pigeons received two simultaneous color discriminations in which the probability of reinforcement for choosing each $\mathrm{S}+$ was equal $\left(\mathrm{A}^{25} \mathrm{~B}^{0}\right.$ and $\left.\mathrm{C}^{25} \mathrm{D}^{0}\right)$. Intermixed among these discrimination trials were single presentations of each $\mathrm{S}+$ with an increase in the probability of reinforcement for responding to one of them $\left(\mathrm{A}^{100}\right)$, but not to the other $\left(\mathrm{C}^{25}\right)$. $\mathrm{Al}-$ though their birds showed a very high and reliable preference for $\mathrm{B}$ over $\mathrm{D}$ on postdiscrimination $\mathrm{B}^{50} \mathrm{D}^{50}$ probe tests $(87.1 \%)$, they made more than twice the number of errors to $D$ than to $B$ on their respective $C^{25} D^{0}$ and $A^{25} B^{0}$ discrimination training trials (52.9 vs. 20.3).

In the present study, we trained rats on two simultaneous object discriminations similar to those developed by Mumby, Pinel, and Wood (1990). In this kind of discrimination, a rat is faced with a pair of small objects, such as a golf ball and a plastic funnel, and must move one of them off a recessed food cup to obtain a morsel of food (a sunflower seed). Table 1 shows the basic design for this and the other three experiments in this study. As is shown in Table 1, the rats in each of the four experiments first received two discrimination training phases prior to preference tests with the nonreinforced objects. In the first training phase of Experiment 1, the rats were exposed to four objects (golf ball, funnel, black studded cylinder, and a wooden block) arranged into two consistent pairs for concurrent simultaneous discriminations, $\mathrm{A}^{1} \mathrm{~B}^{0}$ and $\mathrm{C}^{1} \mathrm{D}^{0}$, where the superscript refers to the number of sunflower seeds obtained for pushing aside each object. Thus, a rat could obtain a single sunflower seed only for pushing aside the $\mathrm{A}$ or the $\mathrm{C}$ object within each pair. In the second training phase, the rats received two 2 -trial sequences in which the first trial of each sequence contained a single presentation of one of the positive objects, followed by the pair of positive and negative objects. Responding to the singly presented A object was rewarded with six seeds, whereas responding to the singly presented $\mathrm{C}$ object continued be rewarded with one seed. Therefore, this phase is characterized as $\mathrm{A}^{6}, \mathrm{~A}^{1} \mathrm{~B}^{0}$ and $\mathrm{C}^{1}, \mathrm{C}^{1} \mathrm{D}^{0}$. Following these training sessions, the rats' preferences for either negative, nonbaited object or positive, baited object were determined on $\mathrm{B}^{1} \mathrm{D}^{1}$ and $\mathrm{A}^{1} \mathrm{C}^{1}$ probe trials, respectively, that were occasionally interspersed among the $\mathrm{A}^{6}, \mathrm{~A}^{1} \mathrm{~B}^{0}$ and $\mathrm{C}^{1}, \mathrm{C}^{1} \mathrm{D}^{0}$ trial sequences (testing phase). Choosing either test object was reinforced with a sunflower seed.

We expected that the rats would not respond more to $\mathrm{D}^{0}$ than to $\mathrm{B}^{0}$, either during initial acquisition of the $\mathrm{A}^{1} \mathrm{~B}^{0}$ and $\mathrm{C}^{1} \mathrm{D}^{0}$ discriminations or during the second training phase of $\mathrm{A}^{6}, \mathrm{~A}^{1} \mathrm{~B}^{0}$ and $\mathrm{C}^{1}, \mathrm{C}^{1} \mathrm{D}^{0}$ trials. According to the VT hypothesis, rats should nonetheless prefer $\mathrm{B}^{1}$ to $\mathrm{D}^{1}$ on $\mathrm{B}^{1} \mathrm{D}^{1}$ probes, because the $\mathrm{A}$ object will have transferred greater positive value to the $\mathrm{B}$ object during the second training phase than the $\mathrm{C}$ object will have transferred to its $\mathrm{D}$ object. They should also prefer $\mathrm{A}^{1}$ to $\mathrm{C}^{1}$ on the $\mathrm{A}^{1} \mathrm{C}^{1}$ probes if the former object has directly acquired greater positive value than the $\mathrm{C}$ object during that phase.

Table 1

The Design of Experiments 1-4

\begin{tabular}{|c|c|c|c|c|c|}
\hline Experiment & Trainin & Phase 1 & Training & Phase 2 & Testing Phase* \\
\hline 1 & $\mathrm{~A}^{1} \mathrm{~B}^{0}$ & $\mathrm{C}^{1} \mathrm{D}^{0}$ & $\mathrm{~A}^{6}, \mathrm{~A}^{1} \mathrm{~B}^{0}$ & $\mathrm{C}^{1}, \mathrm{C}^{1} \mathrm{D}^{0}$ & $\mathrm{~B}^{1} \mathrm{D}^{1} \quad \mathrm{~A}^{1} \mathrm{C}^{1}$ \\
\hline 2 & $\mathrm{~A}^{6} \mathrm{X}^{0}$ & $\mathrm{C}^{1} \mathrm{X}^{0}$ & $\mathrm{~A}^{6} \mathrm{X}^{0}, \mathrm{~A}^{1} \mathrm{~B}^{0}$ & $\mathrm{C}^{1} \mathrm{X}^{0}, \mathrm{C}^{1} \mathrm{D}^{0}$ & $\mathrm{~B}^{1} \mathrm{D}^{1} \quad \mathrm{~B}^{1} \mathrm{X}^{1} \quad \mathrm{D}^{1} \mathrm{X}^{1}$ \\
\hline 3 & $\mathrm{~A}^{1} \mathrm{~B}^{0}$ & $\mathrm{C}^{1} \mathrm{D}^{0}$ & $\mathrm{~A}^{6} \mathrm{X}^{0}, \mathrm{~A}^{1} \mathrm{~B}^{0}$ & $\mathrm{C}^{1} \mathrm{X}^{0}, \mathrm{C}^{1} \mathrm{D}^{0}$ & $\mathrm{~B}^{1} \mathrm{D}^{1} \quad \mathrm{~B}^{1} \mathrm{X}^{1} \quad \mathrm{D}^{1} \mathrm{X}^{1}$ \\
\hline 4 & $\mathrm{~A}^{1} \mathrm{~B}^{0}$ & $\mathrm{C}^{1} \mathrm{D}^{0}$ & $\mathrm{~A}^{6} \mathrm{X}^{0}, \mathrm{~A}^{1} \mathrm{~B}^{0}$ & $\mathrm{C}^{1} \mathrm{Y}^{0}, \mathrm{C}^{1} \mathrm{D}^{0}$ & $\mathrm{~B}^{1} \mathrm{D}^{1} \quad \mathrm{~B}^{1} \mathrm{X}^{1} \quad \mathrm{D}^{1} \mathrm{Y}^{1} \quad \mathrm{X}^{1} \mathrm{Y}^{1}$ \\
\hline
\end{tabular}

Note-Superscripts refer to the number of seeds associated with each object alone and within each pair. * Regular trial sequences from Training Phase 2 also occurred in this phase, as is described in the text. 


\section{Method}

\section{Subjects}

The subjects were 13 experimentally naive male hooded (LongEvans) rats purchased from Charles River Breeding Farms, Quebec. They were approximately 90 days old at the start of the experiment and were maintained at $90 \%$ of their free-feeding weight. They were housed in large group cages (4-5 per cage) in a colony room on a 12:12-h dark:light cycle between experimental sessions. Experimental sessions took place during their dark segments. The rats were kept in individual holding cages during the duration of the experimental session and for approximately $2 \mathrm{~h}$ following it, when they received their daily food rations of 20-25 g Purina rodent chow. They spent the rest of the day in their group cages. This routine was interrupted after each sixth experimental session (Saturday), when the rats were immediately transferred to their group cages and given food ad lib until noon on the following day (Sunday). Experimental sessions resumed at 9:00 a.m. on the next day (Monday). Water was always available in the holding and group cages.

\section{Apparatus}

Four aluminum discrimination chambers, each located in a separate experimental room and elevated $3 \mathrm{~m}$ above the floor, were used. Each rat was assigned to a specif ic chamber throughout the experiment. Each chamber was patterned after those used by Mumby et al. (1990) and consisted of an enclosed, middle $25.4 \times 21.6 \times 40.6 \mathrm{~cm}$ $(1 \times \mathrm{w} \times \mathrm{h})$ start chamber with two black plastic guillotine doors at opposite sides. Raising each door exposed a rat to an open $30.5 \times$ $25.4 \mathrm{~cm}$ platform that extended to a $40.6-\mathrm{cm}$-high end wall. A vertical $9 \times 9 \mathrm{~cm}$ partition extended from the end wall to create two separate goal areas, each containing a 3-cm-diameter, 2-cm-deep recessed food well. Each food well was located $5 \mathrm{~cm}$ from the partition and $3 \mathrm{~cm}$ from the end wall. A flat metal strip under the floor covered each food well and protruded beyond the end wall outside the apparatus. Sliding this strip back and forth from outside the end wall allowed the observer to cover and uncover the food well without being seen by the rat. A $24-\mathrm{V}, 4-\mathrm{W}$ incandescent lamp in a 5-cm diameter cylinder suspended $30 \mathrm{~cm}$ above each food well illuminated this goal area. The only other source of illumination in the running room was a $120-\mathrm{V}, 40-\mathrm{W}$ red incandescent bulb $30 \mathrm{~cm}$ above the middle start chamber. The five small objects, each large enough to cover a food well, were a 4-cm-diameter juice bottle cap, a yellow golf ball, a black metal 35-mm film canister studded with silver round head screws, a 5-cm-high, 5-cm-diameter opaque plastic funnel, and a $4-\mathrm{cm}^{3}$ wooden block. Food wells were baited with shelled, roasted, unsalted sunflower seeds.

\section{Procedure}

The procedure consisted of four phases: a pretraining phase, two training phases, and a test phase.

During pretraining, the rats were shaped to push an object (juice bottle cap) off the food wells for sunflower seeds and then were exposed to the other four objects to determine any prediscrimination object preferences among the six possible pairs. The rats were shaped to push aside the juice bottle cap to acquire the basic response sequence in the discrimination chamber over the first 12 sessions. Each rat learned to leave the start chamber when one of the guillotine doors was raised, approach and push the juice bottle cap off a covered food well, wait for the experimenter to slide off the metal cover exposing the seeds, and then return to the start chamber, where it had to wait for the next trial. In this and all succeeding phases of this experiment, the observer turned off the goal lights as soon as the animal responded to the reinforced object and ate the seeds in the food cup. The number of seeds a rat obtained for pushing aside the juice cap was reduced from five seeds to one seed over these sessions. Each rat received $15 \mathrm{~min}$ of training or up to 10 trials in each session, whichever came first. While the rat waited in the enclosed start chamber, the observer rebaited food wells, placed the object over one of them, and turned on the goal lights over one set of food wells. Then the experimenter initiated the trial by raising the guillotine door to that platform. The position of the object-covered food well and the platform occurred equally often over trials within a session in a random order, with the restriction that it not occupy the same food well or platform more than twice in a row. During this and subsequent phases, the rats never had to wait more than $10 \mathrm{sec}$ between trials.

Following initial object displacement shaping, the rats received another five sessions with the other four objects. On the first session, each of these objects (golf ball [G], funnel [F], studded film canister $[\mathrm{C}]$, and wooden block [B]) were presented singly over 16 trials in a random sequence, so that each object occurred an equal number of times over each food well on each goal platform. We continued to use a seed as reinforcement for pushing aside an object. The rats' initial object preferences among the six possible pairs of objects (BC, FG, BF, CG, BG, FC) were then assessed over the final four sessions to determine which among the three sets of object pairs (BC/FG, BF/CG, BG/FC) would serve as the $\mathrm{A}^{1} \mathrm{~B}^{0}$ and $\mathrm{C}^{1} \mathrm{D}^{0}$ discriminations for each rat. The rats were exposed to each of the six pairs of objects in a random sequence, so that each pair occurred four times within each of these four 24-trial sessions. Thus, each pair occurred a total of 16 times. The rats were reinforced with a seed for the first object they displaced from a food well on each trial. Approaching, sniffing, or otherwise touching an object without pushing it off the food cup was not counted in determining a rat's response to an object in this or subsequent phases of the experiment.

Sets were selected on the basis of the least amount of differences between object preferences within each pair for each rat. This resulted in the BF/CG set being assigned to 5 rats, the BC/FG set to 6 rats, and the $\mathrm{BG} / \mathrm{CF}$ set to 2 rats. Determination of which object within each pair would be designated A or B and C or D was randomly determined for those pairs in which initial preferences were between 7 and 9 out of 16 choices. An object that was selected 10 or more times, however, was designated either as $\mathrm{D}^{0}$ within the $\mathrm{C}^{1} \mathrm{D}^{0}$ pair or as $\mathrm{A}^{1}$ within the $\mathrm{A}^{1} \mathrm{~B}^{0}$ pair, to create object designations opposite to the $\mathrm{B}$ versus $\mathrm{D}$ preferences predicted by the VT hypothesis.

Training Phase 1. This phase consisted of two concurrent simultaneous discriminations: $\mathrm{A}^{1} \mathrm{~B}^{0}$ and $\mathrm{C}^{1} \mathrm{D}^{0}$. Rats received 16 trials per session, with each pair occurring an equal number of times on each platform in a random order, so that the same pair never appeared on the same platform on more than two trials in a row. Each object also occurred an equal number of times on each food well in a random order, with the same restrictions used during prediscrimination training. It should be noted that both food wells were baited and that each was covered by the metal strip to prevent rats from choosing an object on the basis of differential food odors. An error occurred only when the rat pushed aside the $\mathrm{B}^{0}$ or $\mathrm{D}^{0}$ object. Even though both food cups contained seeds, $\mathrm{A}$ and $\mathrm{C}$ are referred to as baited, and $\mathrm{B}$ and $\mathrm{D}$ are referred to as nonbaited objects. During discrimination trials, the experimenter did not uncover the food cup when a rat pushed aside the nonreinforced object but immediately turned off the lights, whereupon the animal had to return to the start chamber. We employed a correction procedure only on the first session by repeating a trial after an error until the rat chose the baited object. A noncorrection procedure was instituted on all subsequent sessions. The rats were trained to a criterion of 14 correct choices out of 16 trials on each discrimination over two successive sessions.

Training Phase 2. After acquiring both discriminations, the rats received twelve 24-trial sessions in which the odd trials contained only the baited object and the even trials contained both objects in the following two-trial sequences: $\mathrm{A}^{6}, \mathrm{~A}^{1} \mathrm{~B}^{0}$ and $\mathrm{C}^{1}, \mathrm{C}^{1} \mathrm{D}^{0}$. Thus, an $\mathrm{A}^{6}$ trial always preceded an $\mathrm{A}^{1} \mathrm{~B}^{0}$ trial, and a $\mathrm{C}^{1}$ trial always preceded a $\mathrm{C}^{1} \mathrm{D}^{0}$ trial. The rats received six seeds for pushing aside $\mathrm{A}$ when it appeared alone, but only one seed when it appeared with B on the 
following trial. They always received one seed for pushing aside $\mathrm{C}$, whether it appeared alone or with D. Each two-trial sequence occurred an equal number of times in a random order within each session, with the restriction that the same sequence should never occur more than twice in a row. Each singly presented baited object also occurred on the same and opposite platforms an equal number of times in a random order, so that its placements were not systematically associated with that of the same object within a pair.

Test phase. This phase consisted of two series of four 30-trial sessions. In the first series of sessions, every $5^{\text {th }}$ trial was a $\mathrm{B}^{1} \mathrm{D}^{1}$ probe test designed to measure the rats' preferences for these two previously nonreinforced objects. In the second series of sessions, every $5^{\text {th }}$ trial was an $\mathrm{A}^{1} \mathrm{C}^{1}$ probe test designed to measure the rats' preferences for the previously baited objects. A rat received one seed only for the first object it pushed aside on these probe tests, as in the initial pretraining preference sessions. Each session contained six reinforced probe preference tests, for a total of 24 probe preference tests in each test phase. The order of the 2-trial training sequences, $\mathrm{A}^{6}, \mathrm{~A}^{1} \mathrm{~B}^{0}$ and $\mathrm{C}^{1}, \mathrm{C}^{1} \mathrm{D}^{0}$, occurred equally often before each probe preference test trial on a random basis.

\section{Results and Discussion}

In this and subsequent experiments, each rat's performance on each discrimination was measured by the number of errors to each nonreinforced object. The mean performances on each discrimination were compared by a paired $t$ test, to determine whether any observed difference was significant at $p<.05$. We report the standard error $(S E)$ of the mean difference, along with the mean number of errors for each discrimination. We calculated each rat's percentage of choices to $\mathrm{B}^{1}$ within the $\mathrm{B}^{1} \mathrm{D}^{1}$ probes and the percentage of choices to $\mathrm{A}^{1}$ within the $\mathrm{A}^{1} \mathrm{C}^{1}$ probes and analyzed each set of data by a single-sample $t$ test, to determine whether the mean percentage of choices to each object was significantly greater than chance $(50 \%)$ at $p<.05$.

\section{Discrimination Training Trials}

All but 1 rat acquired each $\mathrm{A}^{1} \mathrm{~B}^{0}$ and $\mathrm{C}^{1} \mathrm{D}^{0}$ discrimination task to criterion within 15 sessions during the first training phase. We kept the outlier rat in the experiment, however, because its accuracy over its last 2 sessions was close to criterion (13 instead of 14 correct trials) on the $\mathrm{A}^{1} \mathrm{~B}^{0}$ discrimination and it responded correctly on all 16 trials on the $\mathrm{C}^{1} \mathrm{D}^{0}$ discrimination. The remaining rats required the same number of sessions to reach criterion on each discrimination. Including the outlier, the rats required a mean 8.5 sessions $(S E=0.72)$ to learn this task and averaged slightly, but not significantly, fewer responses to $\mathrm{D}^{0}$ than to $\mathrm{B}^{0}[18.2$ vs. $19.8, S E=1.14 ; t(12)=-1.42]$.

Presenting single $\mathrm{A}^{6}$ and $\mathrm{C}^{1}$ trials before their respective $\mathrm{A}^{1} \mathrm{~B}^{0}$ and $\mathrm{C}^{1} \mathrm{D}^{0}$ trials in the second training phase hardly disrupted accurate responding on each discrimination. On those few times that the rats chose a nonreinforced object, however, they did so twice as often, on average, to $\mathrm{D}^{0}$ than to $\mathrm{B}^{0}[3.2$ vs. $1.6, S E=0.56 ; t(12)=2.88, p<.05$ ]. Although initial discrimination training did not prevent differential nonreinforced responding to the nonbaited objects on subsequent training sessions, it greatly minimized such differences, as compared with those reported by Dorrance et al. (1998, see Table 6). No errors were made within each discrimination during the final test phase. It is noteworthy that prior to testing, the rats made an average of 21.5 total errors both to $\mathrm{D}^{0}$ and to $\mathrm{B}^{0}$.

\section{Preference Probe Tests}

Figure 1 shows the percentage of probe trials on which the rats chose $\mathrm{B}^{1}$ over $\mathrm{D}^{1}$ and $\mathrm{A}^{1}$ over $\mathrm{C}^{1}$. As can be seen in Figure 1 and statistically confirmed, the rats significantly preferred $\mathrm{B}^{1}$ to $\mathrm{D}^{1}$ and $\mathrm{A}^{1}$ to $\mathrm{C}^{1}\left[t_{\mathrm{s}}(12)=3.86\right.$ and 5.50 , respectively]. Our rats' preferences for $\mathrm{B}^{1}$ over $\mathrm{D}^{1}$ replicate pigeons' VT effects (Dorrance et al., 1998). Furthermore, our rats clearly associated a greater reward value to $A$ than to $\mathrm{C}$. Unless one assumes that the slightly greater nonreinforced choices to $\mathrm{D}^{0}$ than to $\mathrm{B}^{0}$ in the second training phase were sufficient to create more conditioned inhibition to the former than to the latter, the differential inhibition hypothesis (Aitken, 1999) is an unlikely explanation for the rats' preferences to $\mathrm{B}^{1}$ over $\mathrm{D}^{1}$. As further evidence that this preference cannot be due solely to greater conditioned inhibition to $\mathrm{D}^{0}$, we note that 3 of the 4 rats that did not respond more to $\mathrm{D}^{0}$ than to $\mathrm{B}^{0}$ during the second training phase still preferred $\mathrm{B}^{1}$ to $\mathrm{D}^{1}$. Furthermore, these 4 rats' average preference to $\mathrm{B}^{1}$ was comparable with that of the 9 other rats that did respond slightly more to $\mathrm{D}^{0}$ than to $\mathrm{B}^{0}$ during the second training phase $[67 \%(S E=9.89 \%)$ vs. $70 \%(S E=5.96 \%) ; t(11)=-0.29, p=.78]$

\section{EXPERIMENT 2}

According to the occasion-setting hypothesis (Dorrance et al., 1998), the VT effect should not have occurred if pigeons had learned that $\mathrm{B}^{0}$ signaled a decrease in probability of reinforcement for responding to A when the two stimuli were paired. The fact that their single $\mathrm{S}+$ presen-

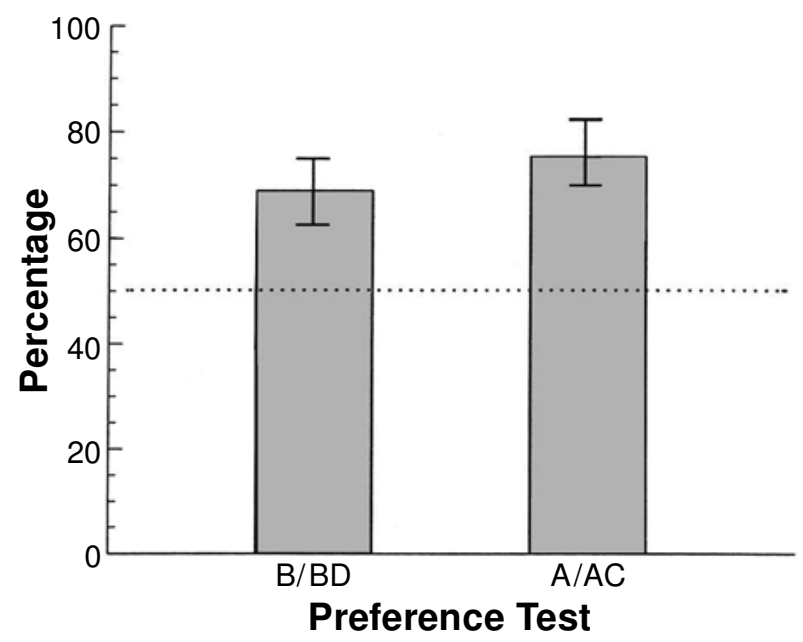

Figure 1. Mean percentage of choices to $B$ out of $24 \mathrm{BD}$ probe trials and to A out of 24 AC probe trials in Phase 3 of Experiment 1 . Vertical error lines show $\pm S E M$ s. The dotted horizontal line depicts chance performance. 
tations were randomly interspersed among their $\mathrm{S}+\mathrm{S}-$ discrimination trials, however, may have hindered pigeons in learning this conditional rule. By contrast, presenting a single, baited object before presenting it with the nonbaited object should have helped the rats in our experiment learn that $\mathrm{B}^{0}$ signaled a reduction in amount of seeds for responding to the A object. However, acquisition of the concurrent $\mathrm{A}^{1} \mathrm{~B}^{0}$ and $\mathrm{C}^{1} \mathrm{D}^{0}$ discriminations before exposure to the $\mathrm{A}^{6}, \mathrm{~A}^{1} \mathrm{~B}^{0}$ and $\mathrm{C}^{1}, \mathrm{C}^{1} \mathrm{D}^{0}$ sequences may have impaired our rats from learning this conditional rule, by reducing their attention to the nonreinforced objects, thus making their absence less noticeable during the second, conditional training phase. The rats may have learned, in other words, which rewarded and nonrewarded objects occurred together and which reinforced object sometimes yielded six seeds rather than one seed, without learning when such an event would occur. Consequently, when faced with the two $S-$ objects on the probe tests, the rats simply associated each with their specific $\mathrm{S}+$ object and made their choice on the basis of which of those $\mathrm{S}+$ objects sometimes delivered more seeds.

According to this reasoning, rats might acquire a conditional rule if they initially experience $\mathrm{A}^{6}$ and $\mathrm{C}^{1}$ before being exposed to the $\mathrm{A}^{6}, \mathrm{~A}^{1} \mathrm{~B}^{0}$ and $\mathrm{C}^{1}, \mathrm{C}^{1} \mathrm{D}^{0}$ sequences. If such a design enhances the differential signaling qualities of $\mathrm{B}^{0}$ and $\mathrm{D}^{0}$, rats should not display the VT effect. Experiment 2 tests this idea. To make Experiment 2 more comparable with Experiment 1, in which rats initially acquired two concurrent simultaneous discriminations, we initially trained the rats with $\mathrm{A}^{6} \mathrm{X}^{0}$ and $\mathrm{C}^{1} \mathrm{X}^{0}$ discriminations, where $\mathrm{X}$ represents another common nonbaited object. Then we exposed them to $\mathrm{A}^{6} \mathrm{X}^{0}, \mathrm{~A}^{1} \mathrm{~B}^{0}$ and $\mathrm{C}^{1} \mathrm{X}^{0}$, $\mathrm{C}^{1} \mathrm{D}^{0}$, rather than to $\mathrm{A}^{6}, \mathrm{~A}^{1} \mathrm{~B}^{0}$ and $\mathrm{C}^{1}, \mathrm{C}^{1} \mathrm{D}^{0}$ training trial sequences. This design allowed us to determine not only whether $\mathrm{B}^{0}$ might become a signal for a reduction in amount of reward at $\mathrm{A}$, but also whether $\mathrm{X}^{0}$ would obtain greater positive value from sometimes being paired with $\mathrm{A}^{6}$ than either $\mathrm{B}^{0}$ or $\mathrm{D}^{0}$, which were always paired with an object baited with one seed. Thus, we exposed the rats to not only to $\mathrm{B}^{1} \mathrm{D}^{1}$ probes, as in Experiment 1, but also to $\mathrm{X}^{1} \mathrm{~B}^{1}$ and $\mathrm{X}^{1} \mathrm{D}^{1}$ probes. According to the occasion-setting hypothesis, rats should prefer $\mathrm{D}^{1}$ over $\mathrm{B}^{1}$ on $\mathrm{B}^{1} \mathrm{D}^{1}$ probes if they had learned that the latter signaled a reduction in amount of reward to its associated $\mathrm{S}+$ object, A. According to the VT hypothesis, rats should prefer $\mathrm{X}^{1}$ on both $\mathrm{X}^{1} \mathrm{~B}^{1}$ and $\mathrm{X}^{1} \mathrm{D}^{1}$ probes.

\section{Method}

\section{Subjects}

Thirteen naive male hooded rats from the same breeding colony served as subjects in this experiment. One animal had to be dropped from the experiment because of illness, so only data from the remaining 12 animals were analyzed.

\section{Apparatus and Materials}

The same object discrimination chambers and materials as those in Experiment 1 were used. An additional object, a white plastic dental floss container, was added to the set of objects from Experiment 1 to be used in the training phases.

\section{Procedure}

We used prediscrimination training procedures similar to those in Experiment 1 to determine prediscrimination object preferences for assigning objects to A, B, C, D, and X categories for each rat. We arranged the five objects into 10 pairs and presented each twice within each of eight 20 -trial sessions. Thus, each pair occurred 16 times. We used the same method for assigning objects to the various reinforced and nonreinforced categories as that in Experiment 1 , so that each possible combination of $\mathrm{A}^{6} \mathrm{X}^{0}, \mathrm{~A}^{1} \mathrm{~B}^{0}, \mathrm{C}^{1} \mathrm{X}^{0}$, and $\mathrm{C}^{1} \mathrm{D}^{0}$ object pairs occurred in at least 2 rats.

The following changes were instituted in the two training phases and in the final test phase. The rats were initially trained with $\mathrm{A}^{6} \mathrm{X}^{0}$ and $\mathrm{C}^{1} \mathrm{X}^{0}$ discriminations over twelve 16-trial sessions (Training Phase 1), for a total of 96 trials for each discrimination. During the next phase (Training Phase 2), the rats continued to receive these two discriminations and the two additional discriminations $\mathrm{A}^{1} \mathrm{~B}^{0}$ and $C^{1} D^{0}$ in the following sequences: $A^{6} \mathrm{X}^{0}, \mathrm{~A}^{1} \mathrm{~B}^{0}$ and $\mathrm{C}^{1} \mathrm{X}^{0}, \mathrm{C}^{1} \mathrm{D}^{0}$. Twelve 24-trial sessions were run, resulting in a total of 72 trials for each discrimination. The final, test phase consisted of twelve 30trial sessions in which every 5th trial was a probe that tested for a rat's preference between two of the three $S-$ objects, B, D, and X. The rats received each of three different types of preference probes, $\mathrm{B}^{1} \mathrm{D}^{1}, \mathrm{X}^{1} \mathrm{~B}^{1}$, and $\mathrm{X}^{1} \mathrm{D}^{1}$, twice within each test session, for a total of 24 preference probes each. The order of the 2-trial training sequences, $\mathrm{A}^{6} \mathrm{X}^{0}, \mathrm{~A}^{1} \mathrm{~B}^{0}$ and $\mathrm{C}^{1} \mathrm{X}^{0}, \mathrm{C}^{1} \mathrm{D}^{0}$, occurred equally on a random basis before each type of probe test.

\section{Results and Discussion}

\section{Discrimination Training Trials}

During the first discrimination training phase, all the rats acquired each discrimination $\left(\mathrm{A}^{6} \mathrm{X}^{0}\right.$ and $\left.\mathrm{C}^{1} \mathrm{X}^{0}\right)$ to criterion (14 out of 16 correct choices) within the first 10 sessions and averaged slightly, but not significantly, more responses to $\mathrm{X}^{0}$ when it accompanied $\mathrm{C}^{1}$ than when it accompanied $\mathrm{A}^{6}[16.4$ vs. $15.3, S E=1.78 ; t(11)=1.08]$. During the second training phase, all the rats quickly learned each additional concurrent discrimination $\left(\mathrm{A}^{1} \mathrm{~B}^{0}\right.$ and $\left.\mathrm{C}^{1} \mathrm{D}^{0}\right)$ by the 8 th session. Although they averaged slightly more responses to $\mathrm{D}^{0}$ than to $\mathrm{B}^{0}$, this difference was not significant $[10.4$ vs. $6.1, S E=2.48 ; t(11)=$ $1.74, .10<p<.20]$. During the test phase, the rats seldom responded to either of these more recently presented $\mathrm{S}-$ objects but again averaged more responses to $\mathrm{D}^{0}$ than to $\mathrm{B}^{0}$, a difference that also failed to reach significance [3.5 vs. $2.0, S E=.31 ; t(11)=1.62, .10<p<.20]$. Although the rats seldom responded to $\mathrm{X}^{0}$ within either the $\mathrm{A}^{6} \mathrm{X}^{0}$ or the $\mathrm{C}^{1} \mathrm{X}^{0}$ discrimination during the test phase, they were more likely to do so when $\mathrm{X}^{0}$ occurred with $\mathrm{C}^{1}$ than when it occurred with $A^{6}$. The rats averaged slightly more responses to $\mathrm{X}^{0}$ when it accompanied $\mathrm{C}^{1}$ than when it accompanied $\mathrm{A}^{6}$ in both the second training phase (2.4 vs. $0.3, S E=0.63)$ and the test phase (1.4 vs. $0.4, S E=$ $0.45)$, but only the difference in the second training phase was significant $[t(11)=4.00]$. When discrimination data were collapsed over all phases, the rats made significantly more responses to $\mathrm{X}^{0}$ when it occurred with $\mathrm{C}^{1}$ than when it occurred with $\mathrm{A}^{6}$ [21.6 vs. $16.2, S E=1.96 ; t(11)=$ 2.77]. They also made more responses to $\mathrm{D}^{0}$ than to $\mathrm{B}^{0}$, but this difference just failed to reach significance [13.8 vs. $8.8, S E=2.82 ; t(11)=1.80, .05<p<.10]$. 


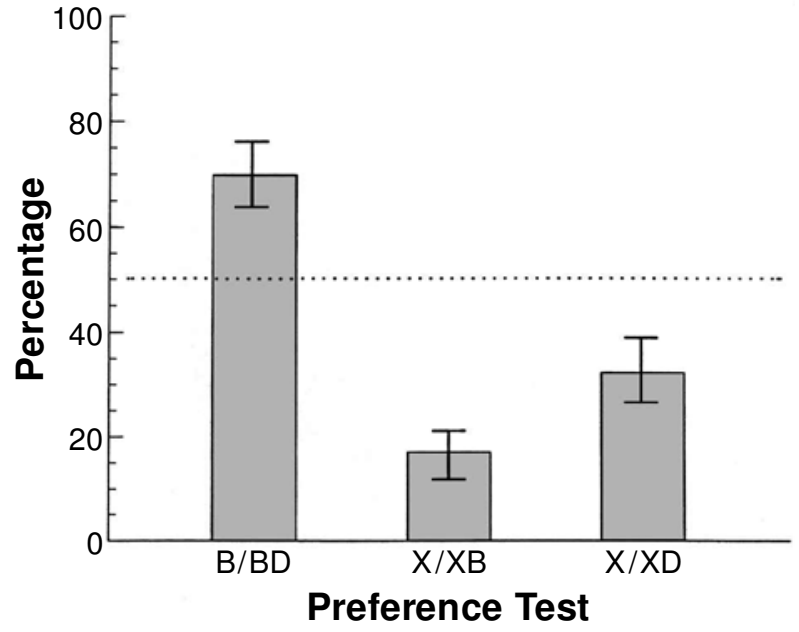

Figure 2. Mean percentage of choices to $B$ out of 24 BD probe trials, to $X$ out of 24 XB probe trials, and to $X$ out of 24 XD probe trials in Phase 3 of Experiment 2. Vertical error lines show $\pm S E M s$. The dotted horizontal line depicts chance performance.

\section{Preference Probe Tests}

Figure 2 shows the percentage of probe trials in which the rats chose $\mathrm{B}^{1}$ over $\mathrm{D}^{1}, \mathrm{X}^{1}$ over $\mathrm{B}^{1}$, and $\mathrm{X}^{1}$ over $\mathrm{D}^{1}$. As can be seen in this figure and statistically confirmed, the rats preferred $\mathrm{B}^{1}$ over $\mathrm{D}^{1}$ significantly above chance $[t(11)=3.29]$ but chose $\mathrm{X}^{1}$ over $\mathrm{B}^{1}$ and over $\mathrm{D}^{1}$ significantly below chance $[t \mathrm{~s}(11)=8.90$ and 2.63 , respectively] In other words, they clearly preferred $\mathrm{B}^{1}$ over $\mathrm{D}^{1}$ and both $\mathrm{B}^{1}$ and $\mathrm{D}^{1}$ over $\mathrm{X}^{1}$. We note, however, that the rats preferred $\mathrm{B}^{1}$ over $\mathrm{X}^{1}$ significantly more than they preferred $\mathrm{D}^{1}$ over $\mathrm{X}^{1}[83 \%$ vs. $68 \% ; t(11)=2.51]$.

The fact that the rats preferred $\mathrm{B}^{1}$ over $\mathrm{D}^{1}$ indicates that $\mathrm{B}^{0}$ did not become an occasion-setting signal for reduction in amount of food under the A object but, instead, gained greater value from $\mathrm{A}$ than $\mathrm{D}^{0}$ gained from $\mathrm{C}$, in accordance with the VT hypothesis. The tendency, albeit a nonsignificant one, for rats to respond more to $\mathrm{D}^{0}$ than to $\mathrm{B}^{0}$ suggests, however, that this difference might have resulted from greater conditioned inhibition to the former. To further test this notion, we compared the $\mathrm{B}^{1}$ preferences of the 7 rats that responded more to $\mathrm{D}^{0}$ than to $\mathrm{B}^{0}$ prior to probe testing with those of the 5 rats that did not show such a difference. The results from this comparison did not support the differential inhibition hypothesis, since the 7 rats that responded more to $\mathrm{D}^{0}$ than to $\mathrm{B}^{0}$ developed a slightly but nonsignificantly lower preference for $\mathrm{B}^{1}$ over $\mathrm{D}^{1}$ than did those 5 rats that did not respond more to $\mathrm{D}^{0}$ than to $\mathrm{B}^{0}[67.0 \%$ $(S E=8.99)$ vs. $73.4 \%(S E=10.75) ; t(10)=-0.46]$.

The fact that the rats preferred $\mathrm{B}^{1}$ over $\mathrm{X}^{1}$ and $\mathrm{D}^{1}$ over $\mathrm{X}^{1}$, however, is contrary to our expectation that $\mathrm{X}^{0}$ would become more valued than either $\mathrm{B}^{0}$ or $\mathrm{D}^{0}$ from being sometimes paired with $\mathrm{A}^{6}$. These preferences are more in line with the differential inhibition hypothesis. Initial training on the concurrent $\mathrm{A}^{6} \mathrm{X}^{0}$ and $\mathrm{C}^{1} \mathrm{X}^{0}$ discriminations produced significantly more nonreinforced responses to $\mathrm{X}^{0}$ paired with $\mathrm{A}^{6}$ than to $\mathrm{B}^{0}$ paired with $\mathrm{A}^{1}[16.2$ vs. 8.8, $S E=2.63 ; t(11)=2.81]$. The rats also appeared to respond more to $\mathrm{X}^{0}$ than to $\mathrm{D}^{0}$ when both were paired with $\mathrm{C}^{1}$, but this difference failed to reach significance [21.6 vs. $13.8, S E=4.79 ; t(11)=1.62, .10<p<.20$ ]. Apparently, the rats developed greater conditioned inhibition to $\mathrm{X}^{0}$ than to $\mathrm{B}^{0}$ and perhaps also to $\mathrm{D}^{0}$. The fact that the rats preferred $\mathrm{B}^{1}$ to $\mathrm{X}^{1}$ more than they preferred $\mathrm{D}^{1}$ to $\mathrm{X}^{1}$ might have resulted from the more reliable differences in conditioned inhibition between the first and the second pair of $\mathrm{S}-$ objects.

\section{EXPERIMENT 3}

Along with further evidence for value transfer from an $\mathrm{S}+$ to its paired $\mathrm{S}-$ object, Experiment 2 also pointed to the operation of differential inhibition in determining preferences between $\mathrm{S}-$ objects. That is, initial acquisition of concurrent $\mathrm{A}^{6} \mathrm{X}^{0}$ and $\mathrm{C}^{1} \mathrm{X}^{0}$ discriminations in Experiment 2 promoted greater conditioned inhibition to $\mathrm{X}^{0}$ than to $\mathrm{B}^{0}$ and possibly to $\mathrm{D}^{0}$ when these latter two objects were paired with $A$ and $C$, respectively. This may be so because, after initially learning to select the $\mathrm{A}$ or the $\mathrm{C}$ object for seeds, the rats would likely continue selecting these objects even when paired with new $\mathrm{S}-$ objects. Therefore, they would not have had the opportunity to develop as much conditioned inhibition to $\mathrm{B}$ or $\mathrm{D}$ as to $\mathrm{X}$.

According to this reasoning, requiring rats initially to acquire concurrent $\mathrm{A}^{1} \mathrm{~B}^{0}$ and $\mathrm{C}^{1} \mathrm{D}^{0}$ discriminations prior to the $\mathrm{A}^{6} \mathrm{X}^{0}$ and $\mathrm{C}^{1} \mathrm{X}^{0}$ discriminations should promote more conditioned inhibition to $\mathrm{B}$ or $\mathrm{D}$ than to $\mathrm{X}$. Consequently, rats should prefer $\mathrm{X}$ to either $\mathrm{B}$ or $\mathrm{D}$ on $\mathrm{X}^{1} \mathrm{~B}^{1}$ and $\mathrm{X}^{1} \mathrm{D}^{1}$ probe tests. If initial concurrent discrimination training does not sufficiently limit rats' ability to notice changes in $\mathrm{S}-$ to an already learned $\mathrm{S}+$, they might also learn that more seeds occur with $\mathrm{A}$ when paired with $\mathrm{X}$ than with $B$ but that no such change occurs with $C$ when paired with $X$ rather than with $D$. Such a conditional rule should counteract any differential inhibition that might otherwise promote preferences for $\mathrm{X}$ over $\mathrm{B}$ on $\mathrm{X}^{1} \mathrm{~B}^{1}$ tests. That is, rats should not display as great a preference for $\mathrm{B}$ over $\mathrm{X}$ as they might for $\mathrm{D}$ over $\mathrm{X}$. If VT operates independently of differential inhibition, rats should also prefer B to D on $\mathrm{B}^{1} \mathrm{D}^{1}$ probes. We tested these predictions in Experiment 3 by initially training rats on concurrent $\mathrm{A}^{1} \mathrm{~B}^{0}$ and $\mathrm{C}^{1} \mathrm{D}^{0}$ discriminations before exposing them to $\mathrm{A}^{6} \mathrm{X}^{0}, \mathrm{~A}^{1} \mathrm{~B}^{0}$ and $\mathrm{C}^{1} \mathrm{X}^{0}, \mathrm{C}^{1} \mathrm{D}^{0}$ trial sequences. Afterwards, we determined their $\mathrm{S}-$ preferences on $\mathrm{X}^{1} \mathrm{~B}^{1}, \mathrm{X}^{1} \mathrm{D}^{1}$, and $\mathrm{B}^{1} \mathrm{D}^{1}$ probes.

\section{Method}

\section{Subjects and Procedure}

Thirteen naive male hooded rats from the same breeding colony were trained in exactly the same manner as the rats in Experiment 2, except for the type of concurrent discriminations in the first training phase. As has already been mentioned, the rats were first trained with concurrent $\mathrm{A}^{1} \mathrm{~B}^{0}$ and $\mathrm{C}^{1} \mathrm{D}^{0}$ discriminations over 12 sessions 
(72 trials per discrimination) before receiving the same conditional training and testing phases as those in Experiment 2.

\section{Results}

\section{Discrimination Training Trials}

All the rats acquired both concurrent $\mathrm{A}^{1} \mathrm{~B}^{0}$ and $\mathrm{C}^{1} \mathrm{D}^{0}$ discriminations to criterion within their first 10 sessions without making more errors to $\mathrm{D}^{0}$ than to $\mathrm{B}^{0}$. During the next two phases, the rats seldom, if ever, responded to either of these $S-$ objects. As was already noted, the rats in the previous experiments sometimes showed a slight tendency to respond more to $\mathrm{D}^{0}$ than to $\mathrm{B}^{0}$. In the present experiment, however, rats made slightly but nonsignificantly fewer responses to $\mathrm{D}^{0}$ than to $\mathrm{B}^{0}$ averaged over all three phases $[14.8$ vs. $17.8, S E=1.67 ; t(12)=-1.78, .10<p<.20]$. Although all the rats also quickly acquired each $\mathrm{A}^{6} \mathrm{X}^{0}$ and $\mathrm{C}^{1} \mathrm{X}^{0}$ discrimination by making only a few errors to the common nonbaited object, they averaged almost twice as many responses to $\mathrm{X}^{0}$ when it accompanied $\mathrm{C}^{1}$ than when it accompanied $\mathrm{A}^{6}$ over the second and third phases [5.8 vs. $3.1, S E=0.89 ; t(12)=3.04, p<.05]$. As was expected, the rats made significantly more responses, on average, to $\mathrm{B}^{0}$ than to $\mathrm{X}^{0}$ when both were paired with the baited A object [17.8 vs. 3.1, $S E=1.64 ; t(12)=8.97]$ and to $\mathrm{D}^{0}$ when both were paired with the baited $\mathrm{C}$ object $[14.8$ vs. 5.8, $S E=1.69 ; t(12)=5.39]$.

\section{Preference Probe Tests}

Figure 3 shows the percentage of probe trials on which the rats chose $\mathrm{B}^{1}$ over $\mathrm{D}^{1}, \mathrm{X}^{1}$ over $\mathrm{B}^{1}$, and $\mathrm{X}^{1}$ over $\mathrm{D}^{1}$. As can be seen in this figure, the rats appeared to prefer $\mathrm{B}^{1}$ over $\mathrm{D}^{1}$ and $\mathrm{X}^{1}$ over both $\mathrm{B}^{1}$ and $\mathrm{D}^{1}$. Whereas their preferences for $\mathrm{X}^{1}$ over $\mathrm{B}^{1}$ and over $\mathrm{D}^{1}$ were significantly above chance $[t \mathrm{~s}(12)=6.24$ and 5.38, respectively], their preference for $\mathrm{B}^{1}$ over $\mathrm{D}^{1}$ was not $[t(12)=1.58, .10<p<$

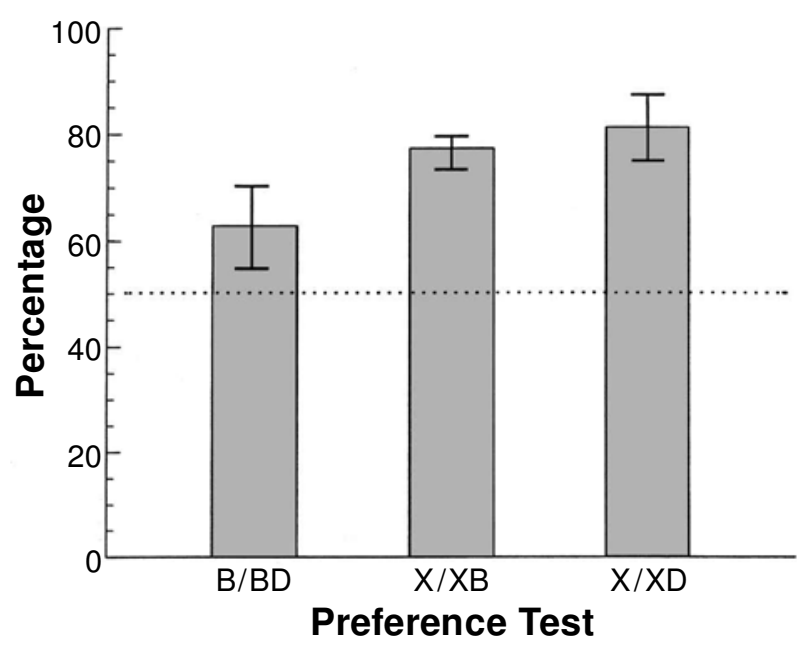

Figure 3. Mean percentage of choices to $B$ out of 24 BD probe trials, to $X$ out of 24 XB probe trials, and to $X$ out of 24 XD probe trials in Phase 3 of Experiment 3. Vertical error lines show $\pm S E M$ s. The dotted horizontal line depicts chance performance.
.20]. The failure to obtain a significant preference for $B^{1}$ over $\mathrm{D}^{1}$ seemed to result from 1 rat's uncharacteristically preferring $\mathrm{D}^{1}$ on all but one $\mathrm{B}^{1} \mathrm{D}^{1}$ probe trial. When the data from this outlier were removed, the remaining 12 rats averaged $67.7 \%$ ( $S E=6.96 \%)$ of their choices to $\mathrm{B}^{1}$, which was comparable with that in Experiment 2 and also was significantly above chance $[t(11)=2.54]$. Furthermore, the 9 rats in this experiment that preferred $\mathrm{B}^{1}$ over $\mathrm{D}^{1} \mathrm{did}$ so to the same extent as those 9 rats in Experiment 2 (79\% vs. $78 \%)$. Therefore, we consider that the rats in this experiment probably also preferred $\mathrm{B}^{1}$ over $\mathrm{D}^{1}$.

The results from this experiment offer somewhat stronger evidence that increasing the reward of a baited object external to its usual discrimination context transfers some of this increased value to its associated nonbaited object. The preferences for $\mathrm{B}^{1}$ over $\mathrm{D}^{1}$ cannot be attributed to differential inhibition, because the rats did not show even a slight tendency to make more errors to $\mathrm{D}^{0}$ than to $\mathrm{B}^{0}$, either in initial training or in the subsequent phases. The rats' preferences for $\mathrm{X}^{1}$ over $\mathrm{B}^{1}$ and $\mathrm{D}^{1}$, on the other hand, reflect a differential inhibition effect owing to more nonreinforced responses to $\mathrm{B}^{0}$ and $\mathrm{D}^{0}$ than to $\mathrm{X}^{0}$. Furthermore, the rats apparently did not use $\mathrm{X}^{0}$ to signal when they would obtain more seeds for choosing A, because they did not significantly differ in their preferences for $\mathrm{X}^{1}$ over $\mathrm{B}^{1}$ from that for $\mathrm{X}^{1}$ over $\mathrm{D}^{1}[t(12)=-0.66]$.

\section{EXPERIMENT 4}

The results from Experiment 3 indicate that both VT and differential inhibition determined the rats' preferences to nonbaited objects during probe tests. Greater conditioned inhibition to initially acquired nonbaited objects, B and D, than to a more recently acquired nonbaited object, X, most likely accounted for preferences for the latter over the former. The apparent VT effect was indicated by the rats' preference for $\mathrm{B}^{1}$ to $\mathrm{D}^{1}$ and suggests that the rats did not learn when responding to the A object would produce more seeds.

The failure of rats to learn that $\mathrm{X}^{0}$ signaled an increase in reward for choosing $\mathrm{A}$ in the second training phase may have resulted from $\mathrm{X}^{0}$ s being paired with both $\mathrm{A}^{6}$ and $C^{1}$. Thus, the rats may have preferred $B^{1}$ to $D^{1}$ because $\mathrm{B}^{0}$ was a more reliable signal than $\mathrm{X}^{0}$ for the $\mathrm{A}$ object. If $\mathrm{X}^{0}$ had been paired only with $\mathrm{A}^{6}$ the rats might have learned when A contained more seeds and, consequently, would not have preferred $\mathrm{B}^{1}$ to $\mathrm{D}^{1}$. To test this idea, we modified the design of Experiment 3 by pairing $X^{0}$ with $\mathrm{A}^{6}$ and a different object, $\mathrm{Y}^{0}$, with $\mathrm{C}^{1}$. As in Experiment 3 , we initially trained the rats on concurrent $\mathrm{A}^{1} \mathrm{~B}^{0}$ and $\mathrm{C}^{1} \mathrm{D}^{0}$ discriminations but then exposed the rats to $\mathrm{A}^{6} \mathrm{X}^{0}, \mathrm{~A}^{1} \mathrm{~B}^{0}$ and $\mathrm{C}^{1} \mathrm{Y}^{0}, \mathrm{C}^{1} \mathrm{D}^{0}$ trial sequences in the second training phase. During the final test phase, we presented the rats with four different test preference probes: $\mathrm{B}^{1} \mathrm{D}^{1}, \mathrm{X}^{1} \mathrm{Y}^{1}, \mathrm{X}^{1} \mathrm{~B}^{1}$, and $\mathrm{Y}^{1} \mathrm{D}^{1}$.

This experiment allowed us not only to separately test for VT and differential inhibition effects, but also to determine whether the latter might obscure the former. Ac- 
cording to the VT hypothesis, rats should prefer $\mathrm{X}^{1}$ to $\mathrm{Y}^{1}$, but not $\mathrm{B}^{1}$ to $\mathrm{D}^{1}$, if they had learned which of the four nonbaited objects only accompanied or set the occasion for $A^{6}$. According to the differential inhibition hypothesis, rats should also prefer $\mathrm{X}^{1}$ to $\mathrm{B}^{1}$ and $\mathrm{Y}^{1}$ to $\mathrm{D}^{1}$ if more nonreinforced responses occur during acquisition of the initial $\mathrm{A}^{1} \mathrm{~B}^{0}$ and $\mathrm{C}^{1} \mathrm{D}^{0}$ discriminations than during subsequent $\mathrm{A}^{6} \mathrm{X}^{0}$ and $\mathrm{C}^{1} \mathrm{Y}^{0}$ discriminations. Finally, if the differential inhibition effect on preferences is not so overpowering, those caused by the VT effect should add to those from differential inhibition to promote a greater preference for $\mathrm{X}^{1}$ over $\mathrm{B}^{1}$ than for $\mathrm{Y}^{1}$ over $\mathrm{D}^{1}$.

\section{Method}

\section{Subjects, Materials, and Procedure}

Thirteen naive, male hooded rats from the same breeding colony as that in the preceding experiments were used. A sixth object, a vertical 1-cm-diameter, 4-cm-long wooden dole attached to a $2.5-\mathrm{cm}^{2}$ wooden platform was added the other five objects from Experiment 3 to make up the A, B, C, D, X, and Y objects. Each of the 12 possible pairs of objects was presented twice in each of the eight 24trial sessions during the pretraining, object preference phase.

The rats were initially trained with $\mathrm{A}^{1} \mathrm{~B}^{0}$ and $\mathrm{C}^{1} \mathrm{D}^{0}$ discriminations over twelve 16-trial sessions in Training Phase 1, for a total of 96 trials for each discrimination. During Training Phase 2, the rats continued to receive these two discriminations, along with the two additional discriminations, $\mathrm{A}^{6} \mathrm{X}^{0}$ and $\mathrm{C}^{1} \mathrm{Y}^{0}$, in the following sequences: $\mathrm{A}^{6} \mathrm{X}^{0}, \mathrm{~A}^{1} \mathrm{~B}^{0}$ and $\mathrm{C}^{1} \mathrm{Y}^{0}, \mathrm{C}^{1} \mathrm{D}^{0}$. Twelve 24-trial sessions, yielding a total of 72 trials for each discrimination, were run in Phase 2. The final test phase consisted of twelve 40-trial sessions, during which every 5 th trial was a preference probe. The rats received four different types of preference probes- $\mathrm{B}^{1} \mathrm{D}^{1}, \mathrm{X}^{1} \mathrm{Y}^{1}, \mathrm{X}^{1} \mathrm{~B}^{1}$, and $\mathrm{Y}^{1} \mathrm{D}^{1}-$ twice within each test session, for a total of 24 trials per probe. Each 2-trial training sequence, $\mathrm{A}^{6} \mathrm{X}^{0}, \mathrm{~A}^{1} \mathrm{~B}^{0}$ and $\mathrm{C}^{1} \mathrm{Y}^{0}, \mathrm{C}^{1} \mathrm{D}^{0}$, occurred for an additional 96 trials.

\section{Results and Discussion}

\section{Discrimination Training Trials}

Except for 1 rat that needed 13 sessions, the remaining rats acquired the concurrent $\mathrm{A}^{1} \mathrm{~B}^{0}$ and $\mathrm{C}^{1} \mathrm{D}^{0}$ discriminations to criterion within 12 sessions. The rats averaged a comparable number of errors to $\mathrm{D}^{0}$ and to $\mathrm{B}^{0}$ during Training Phase 1 [23.8 vs. 24.1, $S E=2.14 ; t(12)=-0.19$ ], Training Phase 2 [2.1 vs. $2.3, S E=0.88 ; t(12)=-0.26$ ], and the test phase [2.2 vs. $2.3, S E=0.72 ; t(12)=-0.11$. They also made a comparable number of errors to $\mathrm{Y}^{0}$ and to $\mathrm{X}^{0}$ during Training Phase 2 [4.9 vs. 6.6, $S E=1.15$; $t(12)=-1.61]$ and during the test phase [3.1 vs. 3.5, $S E=0.81 ; t(12)=-0.47]$. As was expected, every rat made more errors to $\mathrm{B}^{0}$ than to $\mathrm{X}^{0}(26.4$ vs. 6.8$)$ and to $\mathrm{D}^{0}$ than to $\mathrm{Y}^{0}(28.7$ vs. 4.9$)$.

\section{Preference Probe Tests}

Figure 4 shows the percentage of probe trials on which the rats chose $\mathrm{B}^{1}$ over $\mathrm{D}^{1}, \mathrm{X}^{1}$ over $\mathrm{Y}^{1}, \mathrm{X}^{1}$ over $\mathrm{B}^{1}$, and $\mathrm{Y}^{1}$ over $\mathrm{D}^{1}$. As can be seen in this figure and statistically confirmed, the rats significantly preferred $\mathrm{X}^{1}$ over $\mathrm{Y}^{1}[t(12)=$ 12.45], but not $\mathrm{B}^{1}$ over $\mathrm{D}^{1}[t(12)=-0.18]$. The fact that the rats preferred $\mathrm{X}^{1}$ over $\mathrm{Y}^{1}$ without having made more er-

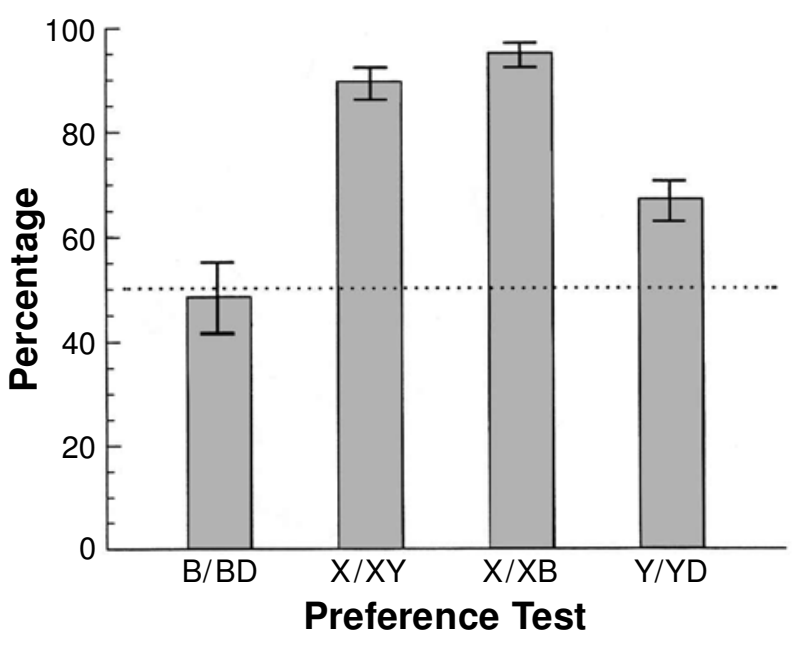

Figure 4. Mean percentage of choices to $B$ out of $24 \mathrm{BD}$ probe trials, to $X$ out of $24 X Y$ probe trials, to $X$ out of 24 XB probe trials, and to $Y$ out of 24 YD probe trials in Phase 3 of Experiment 4. Vertical error lines show $\pm S E M$ s. The dotted horizontal line depicts chance performance.

rors within the $\mathrm{A}^{6} \mathrm{X}^{0}$ than within the $\mathrm{C}^{1} \mathrm{Y}^{0}$ discrimination indicates that this effect is attributable to VT, and not to differential inhibition. That is, this preference occurred because $\mathrm{X}^{0}$ gained greater positive value from being paired with $\mathrm{A}^{6}$ than did $\mathrm{Y}^{0}$ from being paired with $\mathrm{C}^{1}$. Furthermore, the fact that the rats chose $\mathrm{B}^{1}$ about as often as $\mathrm{D}^{1}$ indicates that both $\mathrm{B}^{0}$ and $\mathrm{D}^{0}$ gained equivalent positive value from their respective baited objects, $\mathrm{A}^{1}$ and $\mathrm{C}^{1}$. Taken together, these findings suggest that the rats learned that $\mathrm{X}$ signaled when more seeds would occur under the A object.

As also can be seen in this figure and statistically confirmed, the rats significantly preferred $\mathrm{X}^{1}$ to $\mathrm{B}^{1}$ and $\mathrm{Y}^{1}$ to $\mathrm{D}^{1}[t \mathrm{~s}(12)=27.42$ and 3.28 , respectively]. Both of these results can be attributed to a differential inhibition factor, because all the rats made more nonreinforced responses to $\mathrm{B}^{0}$ than to $\mathrm{X}^{0}(26.4$ vs. 6.8$)$ and to $\mathrm{D}^{0}$ than to $\mathrm{Y}^{0}(28.7 \mathrm{vs}$. 4.9) within their respective discriminations prior to probe tests. That a VT effect also added to a general differential inhibition effect is also evident in Figure 4 and is statistically confirmed by the fact that the rats significantly preferred $\mathrm{X}^{1}$ to $\mathrm{B}^{1}$ more than they preferred $\mathrm{Y}^{1}$ to $\mathrm{D}^{1}[t(12)=$ 5.64].

Finally, we note that the VT effect, as measured by proportion of choices to $\mathrm{X}^{1}$ on the $\mathrm{X}^{1} \mathrm{Y}^{1}$ probes, was considerably greater than that observed in the prior experiments, as measured by proportion of choices to $\mathrm{B}^{1}$ on the $\mathrm{B}^{1} \mathrm{D}^{1}$ probes. Although the rats were not randomly assigned among the different experiments, we carried out independent $t$ tests that revealed a significantly greater VT effect in this experiment than was found in the first $[t(24)=3.54]$, second $[t(23)=2.97]$, or third $[t(24)=3.10]$ experiment. Provided that these differences were not caused by uncontrolled selection biases, they suggest that the VT effect is greater within than outside the discrimination context. 


\section{GENERAL DISCUSSION}

The results from the present study support both the value transfer hypothesis (Dorrance et al., 1998) and the differential inhibition hypothesis (Aitken, 1999) in accounting for preferences between negative stimuli from concurrent simultaneous discriminations. That is, rats will prefer one $\mathrm{S}$ - over the other either if the former has been paired with an $\mathrm{S}+$ of greater positive value than the latter (VT effect) or if rats make more nonreinforced responses to the latter (differential inhibition effect). Our findings clearly show, however, that these effects are independent of each other and that the VT effect cannot be considered merely an artifact of the other (Aitken, 1999). This assertion is based on the fact that we were able to obtain VT effects under conditions designed to prevent rats from responding more to the $\mathrm{S}-$ paired with the less rewarding $\mathrm{S}+$ than to the $\mathrm{S}-$ paired with the more rewarding $\mathrm{S}+$.

Our study demonstrates that the VT effect generalizes to rats trained on concurrent simultaneous object discriminations where the value of one of the positive objects is manipulated by varying amount rather than probability of reinforcement. Moreover, rats showed the VT effect, as did pigeons, when the $\mathrm{S}+$ was made more rewarding while paired with the target $S-$ (Experiment 4 ) or in its absence (Experiments 1, 2, and 3). Although our study replicates Dorrance et al. (1998) and Zentall and Sherburne (1994, Experiment 2), they obtained equivalent VT effects in pigeons by varying the value of $S+$ either within or outside the discrimination context, whereas we found a greater VT effect by increasing the value of the $\mathrm{S}+\mathrm{ob}-$ ject within the discrimination context (Experiment 4) than was found outside the discrimination (Experiments 1,2, and 3). Several factors might account for these differences, not the least of which are the type of animal (rats vs. pigeons), the method of manipulating $\mathrm{S}+$ value (amount vs. probability of reward), and the type of stimuli (actual objects vs. colors on pecking keys). Given these and other possible differences, we cannot attempt to explain this difference in results.

In attempting to eliminate a potential confounding factor of differential inhibition, we inadvertently introduced it as a contributing influence for some of the other preference tests in the last three experiments. Since the rats made more responses to the original than to the more recently introduced $\mathrm{S}-$ objects during simultaneous discriminations, they most likely developed less conditioned inhibition to the latter than to the former. As has already been discussed, such differential inhibition accounts for the rats' preferences for the second over the initial $S-$ objects on certain probe tests $\left(\mathrm{B}^{1}\right.$ over $\mathrm{X}^{1}$ and $\mathrm{D}^{1}$ over $\mathrm{X}^{1}$ in Experiment 2 ; $\mathrm{X}^{1}$ over $\mathrm{B}^{1}$ and $\mathrm{X}^{1}$ over $\mathrm{D}^{1}$ in Experiment 3 ; $\mathrm{X}^{1}$ over $\mathrm{B}^{1}$ and $\mathrm{Y}^{1}$ over $\mathrm{D}^{1}$ in Experiment 4 ). However, as was already noted, these differential inhibition effects were not strong enough to overshadow VT effects in the last two experiments.

Although the VT effect cannot be considered an artifact of differential inhibition between negative stimuli, the question concerning the mechanism responsible for it remains. The fact that Dorrance et al. (1998) and we show that the VT effect can be achieved by varying $S+$ 's value external to the discrimination eliminates the idea that it requires that $\mathrm{S}-$ become directly associated with $\mathrm{S}+$ 's greater reinforcement through trace conditioning. Findings from other studies (Dorrance \& Zentall, 1999; Zentall et al., 1996) in which the transferred value to $S-$ is retroactively affected by varying the value of $S+$ following initial discrimination training offer further evidence against this notion. Zentall et al. (1996) proposed a form of higher order conditioning by which $\mathrm{S}-$ becomes indirectly associated with $\mathrm{S}+$ 's reinforcement (US) through its association with, or signaling of, the presence of $\mathrm{S}+$. According to this notion, varying the value of $S+$ following acquisition of the $\mathrm{S}+\mathrm{S}-$ discrimination should affect the value of an $S-$ because it signals $S+$, but varying the value of $S-$ should have no effect on the value of $S+$, which does not signal $\mathrm{S}-$. When such variations have been carried out by reinforcing responses to $\mathrm{S}-$ or by extinguishing them to $\mathrm{S}+$, however, a bidirectional rather than a unidirectional effect has been seen. That is, reducing S+'s positive value also reduced its $S-$ 's transferred positive value, as was predicted, and reducing $S$-'s negative value increased its S+'s positive value (Dorrance \& Zentall, 1999; Zentall et al., 1996). Dorrance and Zentall proposed that one way to account for these contradictory effects might be to assume that positive value transfer from $\mathrm{S}+$ to its $\mathrm{S}-$ operates through higher order conditioning but that positive value transfer from reinforcing a prior $S-$ to $\mathrm{S}+$ represents weakening of the within-event association between $\mathrm{S}+$ and $\mathrm{S}-$.

Whether rats will also display complexity of $\mathrm{S}-$ and $\mathrm{S}+$ value transfer similar to that shown by pigeons remains to be seen. However, our findings are more in accordance with a higher order conditioning than with a trace conditioning mechanism account of the VT effect. Following Zentall et al. (1996), we propose that rats learn two types of associations from concurrent simultaneous object discriminations: specific reward values (e.g., number of seeds available) for each object and which objects occur together. Thus, a rat will learn that a specific $\mathrm{S}-$ object yields no food but signals a specific $\mathrm{S}+$ object near it from which it may always receive a specific amount or varying amounts of food. The results from the first three experiments further suggest that rats do not combine these two associations into a conditional one to determine when they can obtain more food from the $\mathrm{S}+\mathrm{ob}-$ ject. That is, rats only acquired higher order associations between $\mathrm{B}-$ and $\mathrm{A}+$ and between $\mathrm{D}-$ and $\mathrm{C}+$ and developed greater transferred value from $A+$ to $B-$ than from $\mathrm{C}+$ to $\mathrm{D}-$ because $\mathrm{A}+$ sometimes yielded one and sometimes six seeds but $\mathrm{C}+$ gave up only one seed. This occurred despite that fact that presenting A either alone (Experiment 1) or with another nonreinforced object (X, Experiments 2 and 3 ) was a valid cue for predicting when A would yield six seeds. Failure to acquire such a conditional association probably preserved the VT effect seen 
in our first three experiments. The fact that $\mathrm{X}$ occurred with the lower valued $\mathrm{C}$ object equally often as with the more highly valued A object might have prevented rats from learning when A would give up more seeds. When $\mathrm{X}^{0}$ occurred only with $\mathrm{A}^{6}$ and $\mathrm{B}^{0}$ only with $\mathrm{A}^{1}$ (Experiment 4 ), the rats were able to determine when responding to A would produce greater reward, which prevented VT differences between $B$ and $D$ but produced them between $\mathrm{X}$ and $\mathrm{Y}$. The question remains whether the rats would have eventually learned a conditional association for predicting the amount of seeds under A with more extensive training in the first three experiments. If they could, VT differences between B and D would have disappeared in these experiments and emerged between $\mathrm{X}$ and $\mathrm{B}$ or D in Experiments 2 and 3.

In explaining the VT as an example of higher order conditioning, Dorrance and Zentall (1999) suggested that it occurs because pigeons sometimes attend to $S-$ before they respond to $\mathrm{S}+$ for reinforcement on some trials. Casual observations of our rats' behavior after learning the simultaneous object discriminations suggest that they often employed a response chain of first approaching the negative object and inspecting (nosing) it without pushing it off the food well and then going over to the positive object and quickly and forcefully pushing it off its well. The rats seldom if ever went back to the negative object after having selected the positive one. Our procedures discouraged rats from lingering in the goal area after displacing an object so that rats had little option but to either go directly to the baited object or select it if they accidently approached the nonrewarded object. According to this higher order association account, differences in VT should be eliminated if we could train rats to go back to the negative object after choosing the positive one be- fore they could reenter the start chamber for the next trial. A test of this prediction awaits further experimentation.

\section{REFERENCES}

Aitken, M. R. F. (1999). Alternative accounts are preferable to value transfer theory: Commentary on Dorrance, Kaiser, and Zentall (1998). Animal Learning \& Behavior, 27, 490-493.

Clement, T. S., Weaver, J. E., Sherburne, L. M., \& Zentall, T. R. (1998). Simultaneous discrimination learning in pigeons: Value of $\mathrm{S}-$ affects the relative value of its associated S+. Quarterly Journal of Experimental Psychology, 51B, 363-378.

Dorrance, B. R., Kaiser, D. H., \& Zentall, T. R. (1998). Value transfer in a simultaneous discrimination by pigeons: The value of $\mathrm{S}+$ is not specific to the simultaneous discrimination context. Animal Learning \& Behavior, 26, 257-263.

Dorrance, B. R., \& Zentall, T. R. (1999). Within-event learning contributes to value transfer in simultaneous instrumental discriminations by pigeons. Animal Learning \& Behavior, 27, 206-210.

Fersen, L. von, Wynne, C. D. L., Delius, J. D., \& Staddon, J. E. R. (1991). Transitive inference formation in pigeons. Journal of Experimental Psychology: Animal Behavior Processes, 17, 334-341.

Mumby, D. G., Pinel, J. P. J., \& Wood, E. R. (1990). Non-recurringitems delayed nonmatching-to-sample in rats: A new paradigm for testing nonspatial working memory. Psychobiology, 18, 321-326.

Zentall, T. R., Dorrance, B. R., \& Clement, T. S. (1999). Differential inhibition and stimulus generalization cannot account for value transfer in simultaneous discrimination learning by pigeons. Animal Learning \& Behavior, 27, 494-496.

Zentall, T. R, \& Sherburne, L. M. (1994). Transfer of value from $\mathrm{S}+$ to $\mathrm{S}-$ in a simultaneous discrimination. Journal of Experimental Psychology: Animal Behavior Processes, 20, 176-183.

Zentall, T. R., Sherburne, L. M., Roper, K. L., \& Kraemer, P. J. (1996). Value transfer in a simultaneous discrimination appears to result from within-event Pavlovian conditioning. Journal of Experimental Psychology: Animal Behavior Processes, 22, 68-75.

(Manuscript received February 6, 2001; revision accepted for publication July 30, 2001.) 